\title{
Uso de videos en el estudio y comprensión de la Teoría de Sistemas y el Pensamiento de Sistemas: Propuesta de una guía para la búsqueda y selección
}

\author{
Heriberto Niccolas Morales ${ }^{a}$, Jaime Garnica González ${ }^{a}$, Cristian Eduardo Sánchez \\ Ortíz ${ }^{a}$, Itzel San Martín Sampayoa, Germán Reséndiz López ${ }^{b}$, Noel Iván Toto \\ Arellano $^{b}$ y Ángel Monzalvo Hernández \\ ${ }^{a}$ Universidad Autónoma del Estado de Hidalgo, Mineral de la Reforma, Hidalgo, México - \\ hnicolas@uaeh.edu.mx, jgarnica@uaeh.edu.mx,sa368428@uaeh.edu.mx,sa391674@uaeh.edu.mx. \\ ${ }^{\mathrm{b}}$ Universidad Tecnológica de Tulancingo, Tulancingo, Hidalgo, México - gresendizl@utec- \\ tgo.edu.mx, ivantotoarellano@hotmail.com, angelmonzalvo@utec-tgo.edu.mx.
}

\begin{abstract}
Resumen
Como parte de las actividades de innovación educativa que realizan los docentes, se tiene la necesidad de contar con materiales didácticos para el desarrollo de las clases, pero no siempre se dispone del tiempo y recursos necesarios para crearlos. Sin embargo, en Internet existen muchos materiales educativos que pueden ayudar tanto a profesores como a estudiantes en las actividades de enseñanza, aprendizaje o investigación. Muchos de estos recursos son de dominio público o han sido publicados con alguna licencia de propiedad intelectual, mismos que pueden ser aprovechados para entender mejor los temas teóricos que representan complejidad por su nivel de abstracción, como puede ser la Teoría General de Sistemas. El objetivo de este trabajo es generar y proponer una guía para la búsqueda y selección de recursos educativos abiertos en modalidad de video, que facilite la actividad de indagación de temas a los estudiantes de ingeniería industrial en asignaturas que tratan la Teoría de Sistemas y el Pensamiento de Sistemas, para que logren el propósito de aprendizaje de contenidos temáticos de una manera rápida y dinámica. El presente artículo describe un trabajo colaborativo realizado entre estudiantes y maestros de la Licenciatura en Ingeniería Industrial que da cuenta de la importancia que tiene el video como recurso de apoyo a las actividades de autoaprendizaje, además de mostrar la utilidad y beneficio del uso de videos en los últimos años.
\end{abstract}

Palabras clave: Recursos Educativos Abiertos, Video educativo, Teoría de Sistemas, Aprendizaje. 
Uso de videos en el estudio y comprensión de la Teoría de Sistemas y el Pensamiento de Sistemas: Propuesta de una guía para la búsqueda y selección

\section{Introducción}

La llegada de Internet a las actividades educativas ha revolucionado por completo la manera de aprender de los estudiantes universitarios en el siglo XXI. En la actualidad los estudiantes tienen acceso a una gran cantidad de bases de datos y documentos en línea y las herramientas de búsqueda cuentan con algoritmos que facilitan la tarea de encontrar documentos con información útil para el autoaprendizaje. Sin embargo, existe la desventaja de que mucha de la información existente no es del todo confiable. Tanto alumnos como docentes se enfrentan a un mar de páginas y documentos cuya información puede ser errónea, incompleta o inclusive falsa, dificultando las tareas de búsqueda. No obstante, Internet está continuamente modificando los hábitos de los usuarios y, a la vez, aporta nuevas posibilidades y planteamientos en las actividades de formación.

Muchas metodologías actuales de aprendizaje utilizan el video como parte integrante de su diseño instruccional básico, tales como la Flipped Classroom o Clase invertida en la que los estudiantes explotan el empleo de este formato para la visión de contenidos y el aprendizaje dentro y fuera del aula. En los últimos años se ha observado una tendencia creciente en el uso de dispositivos móviles con conexión a Internet por parte de la comunidad estudiantil para visionar videos, en muchos casos como información complementaria para aclarar dudas o lograr una mejor comprensión de temas o conceptos vistos en clase que se les dificultan. Sin embargo, es importante desarrollar la habilidad para hacer una búsqueda y selección adecuada de estos materiales. El objetivo de este trabajo es generar y proponer una guía para la búsqueda y selección de recursos educativos abiertos en modalidad de video, que facilite la actividad de indagación de temas a los estudiantes de Ingeniería Industrial en asignaturas que tratan la Teoría de Sistemas y el Pensamiento de Sistemas. Pero puede ser de utilidad para la valoración de cualquier material en video que se quiera usar como apoyo educativo.

\section{Los recursos educativos abiertos (REA)}

Como parte de la evolución que ha tenido la educación superior en la segunda década del siglo XXI, se han desarrollado dos grandes tendencias: "Open access" y "Open education". Las universidades han impulsado el desarrollo de recursos que ponen a disposición de sus estudiantes y el público en general para fortalecer la Sociedad del Conocimiento en sus países. De esta manera, las tendencias indicadas han dado pauta al desarrollo de software de código abierto, definición de los estándares de licenciamiento flexibles y la creación y provisión de contenidos abiertos para cursos en la educación superior, que se constituyeron 
en antecedentes importantes en el surgimiento del movimiento de recursos educativos abiertos, conocidos como REA (Ramírez y Burgos, 2012, p. 10) . Los recursos educativos abiertos (REA) son todos aquellos recursos y materiales didácticos que de forma gratuita se pueden encontrar en Internet y pueden ser identificados como materiales de cursos, módulos, libros, guías, evaluaciones, software, así como cualquier otra herramienta digital empleada para dar soporte al acceso de conocimiento (Atkins, Brown y Hammond, 2007). Los REA también han permitido el desarrollo de los cursos masivos abiertos en línea (MOOCs), que ofrecen una opción de formación a todo aquel interesado en algún tema, en muchos casos sin costo alguno, con tan solo contar con acceso a Internet.

\subsection{El video digital como recurso de apoyo al docente}

La presencia de las Tecnologías de la Información y de la Comunicación (TIC) en los sistemas educativos es una realidad desde finales de la primera década del siglo XXI. El video como herramienta de estudio permite representar variados escenarios del mundo real que pueden ser guardados para reproducirse en el momento que se considere oportuno. En un video se pueden incluir explicaciones con audio, texto, esquemas, mapas, tablas, gráficos e imágenes, combinadas en secuencias para transmitir un mensaje informativo. Los videos tienen la enorme ventaja de que pueden verse las veces que se desee, con la facilidad de hacer pausas, regresar a un punto que se quiera volver a repetir o adelantar en función de las necesidades e intereses de la persona que desea aprender sobre un tema. Es decir, el video, tiene una gran versatilidad que se puede aprovechar como complemento en las actividades docentes. El vídeo digital, es un recurso más en la enseñanza, por ello es importante hacer notar lo que señalan Cabero, Llorente y Gravan (2005), en cuanto a que el beneficio real del uso del video digital como recurso educativo está en la manera en que son empleados para que permitan alcanzar los objetivos de cada programa, de modo que sirva como instrumento de comunicación y alfabetización icónica de los estudiantes.

\subsection{Potencial del video digital como recurso de apoyo entre los jóvenes en etapas de formación}

Algunos estudios como el realizado en España por Fundación Telefónica (2016), muestran la importancia que ha adquirido el video en los últimos años en al ámbito educativo, ya que se ha convertido en un formato fundamental al momento de realizar actividades formativas. Como dato relevante se tiene que el $79.6 \%$ de los internautas recurrieron al vídeo con intenciones formativas. Al analizar por grupos de edad se observó que el $95 \%$ de los jóvenes de edades comprendidas entre los catorce y los diecinueve años y el $91 \%$ de 
Uso de videos en el estudio y comprensión de la Teoría de Sistemas y el Pensamiento de Sistemas: Propuesta de una guía para la búsqueda y selección

jóvenes entre los veinte y los veinticuatro años, utilizó Internet para acceder a vídeos con carácter formativo. El $61.6 \%$ de los jóvenes de edades comprendidas entre los catorce y los diecinueve años y el $60.5 \%$ entre veinte y veinticuatro años utilizaron Internet para acceder a vídeos en el entorno de la educación formal, cuyos segmentos de edad se encuentran centrados en su etapa formativa (Fundación Telefónica, 2016). También es notoria la utilización del video con fines educativos en las universidades de España y esto va en sintonía con el incremento en el interés que los jóvenes muestran por la utilización de Internet con este fin, ya que se tuvo un crecimiento del 62\% entre 2015 y 2016, donde la principal motivación de conectarse a Internet estuvo relacionada con la formación y el aumento de la productividad (Fundación Telefónica, 2016).

En la mayoría de países desarrollados o industrializados que cuentan con una infraestructura de telecomunicaciones sólida y con amplia cobertura del servicio de Internet, se ha observado un incremento en la producción de videos por parte del personal docente de sus universidades. Por otra parte, los videos que ofrecen canales en Internet tales como TED o Youtube, resultan de mucha utilidad para el desarrollo de las clases ya sea en forma presencial o virtual, para debatir, y para abrir la mente de los estudiantes a nuevas ideas y posibilidades (Mosquera, 2017).

En México, el uso del video con fines educativos también goza de popularidad. Esto se debe al poder comunicativo y formativo que tiene sobre los estudiantes, ya que a través de la transmisión de la información contenida, es posible fomentar la discusión y reflexión acerca de los temas tratados. Aun cuando las desigualdades económicas y tecnológicas que prevalecen en las distintas regiones de México hacen amplia la brecha digital, los jóvenes que tienen acceso a la educación de nivel medio superior y superior utilizan Internet para revisar videos que proponen los docentes o que ellos mismos buscan como parte de los procesos de enseñanza aprendizaje, ya que logra atraer su atención hacia un determinado tema, fortalece los conocimientos previos y favorece el aprendizaje significativo. Algunas investigaciones en tecnología educativa realizadas en México, señalan que los estudiantes que han usado el video como recurso de apoyo manifestaron un significativo proceso formativo, generando experiencias de aprendizaje colaborativo dentro de su entorno (Mortera y Villarreal, 2013); también se encontró que muestran alto grado de motivación y satisfacción hacia la modalidad a distancia apoyada en el uso del video como REA (Rodríguez, López y Mortera, 2017).

De acuerdo a la Encuesta Nacional sobre Disponibilidad y Uso de Tecnologías de la Información en los Hogares 2019 (Endutih 2019), el 56.4\% de los hogares en México tiene conectividad, ya sea mediante una conexión fija o móvil, hay 80.6 millones de internautas y 86.5 millones de usuarios de comunicaciones móviles, de los cuales $95.3 \%$ usan teléfono inteligente (Smartphone). El 90.7\% de los usuarios de Internet en México, lo utiliza para la obtención de información. Otro dato relevante de la encuesta es que, el grupo de edad que 
concentra la mayor proporción de usuarios de Internet, es el grupo de 18 a 24 años con una participación del 91.2\% y el segundo grupo de edad donde el uso de Internet está más generalizado, es el de 12 a 17 años, con 87.8\% (INEGI, 2020). Los datos que arroja la Endutih 2019 muestran el crecimiento que está teniendo el uso de las TIC en México y dejan ver la posibilidad de explotar mejor los teléfonos inteligentes en actividades de formación en la población joven.

\section{Teoría General de Sistemas y Pensamiento de Sistemas, implicaciones para su aprendizaje}

La Teoría General de Sistemas (TGS), se ha interpretado como una nueva filosofía de la naturaleza por parte de varios pensadores y practicantes, ya que como toda teoría científica que pretende tener gran alcance contiene aspectos metacientíficos o filosóficos. El Pensamiento de Sistemas (PS) sustentado en la TGS se ha constituido con el paso de los años en una filosofía de los sistemas que instaura una nueva visión del mundo y una reorientación de la forma de observar y entender el mundo, en el que se sustituye al concepto "mecanicista" del universo plasmado a base de leyes deterministas de la naturaleza y de entidades físicas que se mueven al azar. Por lo que la TGS trata de reemplazar el esquema de causalidad lineal por una visión organísmica del mundo como una gran organización, basándose en los postulados de Von Bertalanffy (1976), acerca de los sistemas abiertos que tienen como característica mostrar simplicidad organizada, complejidad no organizada o complejidad organizada, haciendo notar la importancia de aspectos teleológicos (propósito o finalidad) presentes en los sistemas (Johansen, 1986; Checkland, 1993; Van Gigch, 2006). Como puede notarse en la descripción de la TGS y el PS indicada en líneas anteriores, no resulta tan sencillo para los jóvenes estudiantes de Ingeniería Industrial su comprensión y estudio. Los estudiantes por lo general cursan alguna asignatura que aborda la TGS como parte importante de su contenido, incluida en el plan de estudios, ya que en la actividad profesional de un ingeniero industrial tratará con distintos sistemas que sirven de soporte a la operación de una empresa (sistema de producción, sistema logístico, sistema de inventario, sistema de gestión de la calidad, sistema de manufactura), de ahí la importancia del estudio y comprensión de la TGS y el PS.

La mayoría de libros de texto que se utilizan de apoyo para la revisión, estudio y comprensión de la TGS basan su contenido en la obra de Ludwing Von Bertalanffy, quien es considerado como el padre de la TGS. No obstante los libros tienen como característica común utilizar descripciones y explicaciones teóricas extensas y utilizando términos que resultan desconocidos para los jóvenes, además de que en algunas partes llega a ser repetitiva la información. Lo anterior genera en la mayor parte de los estudiantes el deseo 
Uso de videos en el estudio y comprensión de la Teoría de Sistemas y el Pensamiento de Sistemas: Propuesta de una guía para la búsqueda y selección

de abandonar la lectura de los contenidos o realizar una lectura rápida y superficial que abona muy poco o nada al aprendizaje de los temas y conceptos abordados en la TGS, tales como entropía, homeóstasis, recursividad, retroalimentación, neguentropía, sinergia, equifinalidad, emergencia, isomorfismo, caja negra, flujos, por mencionar solo algunos. Lo anterior ha motivado que los docentes y los mismos estudiantes busquen en Internet materiales o recursos de apoyo en forma de video, que permita lograr un mejor aprendizaje y comprensión de los conceptos. En la TGS como en cualquier tema de estudio es complicado para los estudiantes encontrar información que ayude a su mejor comprensión. Algunos estudiantes que han acreditado la asignatura sobre TGS han compartido su experiencia de lo complejo que puede llegar a ser, reforzar el aprendizaje obtenido en clase, por lo que se considera muy conveniente elaborar una guía para evaluar y seleccionar videos que cumplan con indicadores de pertinencia, efectividad y aspectos pedagógicos. Dicha guía puede ser utilizada tanto por estudiantes como por profesores de manera que sea más sencillo el proceso de selección de materiales en video.

\section{Guía para evaluar y seleccionar videos de Internet}

El proceso de introducción y asimilación de la tecnología en las actividades educativas ha sido a ritmos diferenciados de país a país y el rol del docente ha cambiado derivado de ello. Lo anterior ha implicado la alfabetización digital del profesor, para que conozca y maneje adecuadamente las distintas tecnologías y herramientas digitales, que una vez lograda conduce al docente a desarrollar en sus alumnos competencias digitales tales como habilidades comunicativas, pensamiento crítico, capacidad de analizar información y de interpretar y valorar contenidos. Por ello, en este trabajo se presenta una matriz de evaluación y selección de videos que pueden ser encontrados en Internet como recursos educativos abiertos (REA) o material de consulta de libre acceso, con la finalidad de orientar a los docentes y estudiantes en la aplicación de criterios o indicadores que permitan una selección más coherente de estos recursos para incorporarlos como apoyo en las actividades de aprendizaje.

Para la elaboración de la matriz se realizó una revisión documental en Internet de documentos académicos que dan lineamientos, criterios, indicadores y pautas para realizar la valoración de materiales en video o recursos educativos de Internet (Bravo, 2000; Sosisky, Perazzo, Bardi y Ruiz, 2007; Aguilar, 2016; Marquès, 2018; Adame, s.f.). La escala de valoración propuesta considera valores del 1 al 5, donde: $1=$ Pésimo, $2=$ Deficiente, $3=$ Regular, $4=$ Bueno y $5=$ Excelente. Una vez visionado el material se asigna una valoración a cada uno de los indicadores propuestos, agrupados en cinco aspectos (Pertinencia, Efectividad, Técnicos, Originalidad y Pedagógicos). La máxima valoración 
Heriberto Niccolas Morales, Jaime Garnica González, Cristian Eduardo Sánchez Ortiz, Itzel San Martín Sampayo, Germán Reséndiz López, Noel Iván Toto Arellano y Ángel Monzalvo Hernández

que puede alcanzar un video es de 150 puntos (100\%) y la mínima valoración sería de 30 puntos $(20 \%)$. Se considera que un video que alcance los 105 puntos (70\%) o más es recomendable como material de apoyo. En la Figura 1 se muestra la matriz para evaluación y selección de videos de Internet propuesta en el trabajo y que es resultado de la revisión e integración de los esquemas encontrados en la literatura. A manera de ejemplo, se han colocado valores de 5 para cada indicador, obteniendo la suma total de 150 puntos.

\begin{tabular}{|c|c|c|}
\hline No. & Indicadores & Valoración \\
\hline & ASPECTOS DE PERTINENCIA & \\
\hline 1 & $\begin{array}{l}\text { El vocabulario es adecuado (no se utiliza lenguaje agresivo, obsceno, ni palabras } \\
\text { rebuscadas) }\end{array}$ & 5 \\
\hline 2 & Muestra una secuencia lógica adecuada a los propósitos de aprendizaje & 5 \\
\hline 3 & Se explica con claridad cada concepto de acuerdo a la temática de estudio & 5 \\
\hline 4 & Se exponen primero los conceptos sencillos y luego los complejos & 5 \\
\hline 5 & Contiene explicaciones que enlazan con conocimientos previos (es comprensible) & 5 \\
\hline 6 & Se presenta un resumen o síntesis & 5 \\
\hline \multirow[t]{2}{*}{7} & La duración es adecuada para mantener la atención del espectador & 5 \\
\hline & ASPECTOS DE EFECTIVIDAD & \\
\hline 8 & Ayuda al espectador a crear nuevos conocimientos o ampliar los existentes & 5 \\
\hline 9 & Transmite emociones al espectador & 5 \\
\hline 10 & El contenido es relevante para el ejercicio de la profesión & 5 \\
\hline 11 & Es estético a la vista del espectador & 5 \\
\hline \multirow[t]{2}{*}{12} & Invita a verlo de nueva cuenta & 5 \\
\hline & ASPECTOS TÉCNICOS & \\
\hline 13 & Muestra imágenes claras y atractivas (calidad de la imagen) & 5 \\
\hline 14 & Contiene textos, gráficos y animaciones & 5 \\
\hline 15 & Legibilidad de textos, gráficos y tablas & 5 \\
\hline 16 & Calidad de la banda sonora (voces, música, sonidos) & 5 \\
\hline 17 & Planteamiento audiovisual (interacción entre elementos) & 5 \\
\hline 18 & Estructura y ritmo (guión claro, secuenciación adecuada) & 5 \\
\hline \multirow[t]{2}{*}{19} & Dispone o cuenta con documentación de apoyo & 5 \\
\hline & ASPECTOS DE ORIGINALIDAD & \\
\hline 20 & Muestra originalidad en el diseño, imágenes y expresión & 5 \\
\hline 21 & Las ideas o conceptos se presentan de manera creativa e ingeniosa & 5 \\
\hline 22 & Muestra escenas difíciles de recrear en el aula & 5 \\
\hline \multirow[t]{2}{*}{23} & Incluye las referencias de fuentes confiables consultadas para documentar el tema & 5 \\
\hline & ASPECTOS PEDAGÓGICOS & \\
\hline 24 & Los contenidos son adecuados al usuario (calidad, profundidad, organización) & 5 \\
\hline 25 & Apoya o refuerza al logro de los objetivos y/o competencias de la asignatura & 5 \\
\hline 26 & Capta la atención o despierta el interés del espectador & 5 \\
\hline 27 & Se utilizan efectos visuales para captar la atención y mejorar el aprendizaje & 5 \\
\hline 28 & Se utilizan efectos de sonido para captar la atención y mejorar el aprendizaje & 5 \\
\hline 29 & $\begin{array}{l}\text { Presenta una adecuada relación imagen-texto (los textos complementan a las } \\
\text { imágenes) }\end{array}$ & 5 \\
\hline \multirow[t]{3}{*}{30} & Presenta una reflexión creativa sobre el tema, induce al debate sobre el tema & 5 \\
\hline & Puntuación total: & 150 \\
\hline & Porcentaje de cumplimiento: & 100.00 \\
\hline
\end{tabular}

Fig. 1 Matriz de Evaluación y Selección de Videos de Internet (MESVI)

Fuente: Elaboración propia con base en Bravo (2000), Sosisky, Perazzo, Bardi y Ruiz (2007), Aguilar (2016), Marquès (2018) y Adame (s.f.) 
Uso de videos en el estudio y comprensión de la Teoría de Sistemas y el Pensamiento de Sistemas: Propuesta de una guía para la búsqueda y selección

\section{Conclusiones}

La matriz de evaluación y selección de videos propuesta en este trabajo es una guía sencilla, compacta y de fácil manejo tanto para estudiantes como para docentes. Es a su vez un material de apoyo que puede incentivar la incorporación y uso más intensivo de videos digitales de acceso abierto en Internet por parte de los docentes universitarios. Los videos seleccionados con ayuda de la matriz pueden servir como apoyo en las sesiones de clase presenciales en el aula y en actividades fuera de la misma, que ayude a los docentes y estudiantes a generar debates y discusiones sobre los temas tratados y promueva el aprendizaje profundo.

Cabe mencionar que lo expuesto en este trabajo, se deriva de la experiencia de haber probado la guía con alumnos (74) y profesores (6) de las dos instituciones (UAEH y UTT), dando un resultado de aprobación y mejora en las notas de los estudiantes en las asignaturas de sistemas en un promedio del 85\%, en el periodo de agosto a noviembre del 2019. Lo anterior, sirve de aliciente para dar continuidad al trabajo y evaluar resultados en periodos escolares posteriores.

La generación de la guía busca también motivar a los docentes universitarios a que hagan un esfuerzo por producir videos de manera conjunta con sus estudiantes para contar con nuevos recursos en los repositorios institucionales de sus universidades y con ello generar conocimientos y experiencias de aprendizaje colaborativo, disminuir costos y ampliar la cobertura educativa. La educación digital brinda la oportunidad de reflexionar sobre los desafíos a los que nos enfrentamos como docentes y a emprender acciones que lleven a mejorar la calidad educativa.

\section{Agradecimientos}

Este proyecto ha sido apoyado por el Consejo Nacional de Ciencia y Tecnología bajo el proyecto A1-S-20925 del "Fondo Sectorial de Investigación para la Educación.

\section{Referencias}

Adame, S. I. (s.f.). Instrumento para evaluar Recursos Educativos Digitales, LORI - AD. Fecha de consulta 2 de abril de 2020. Recuperado de https://files.sld.cu/redenfermeria/files/2019/02/InstrumentoparaevaluarREA.pdf

Aguilar, J. E. (2016). Diseño y elaboración de recursos didácticos para el aprendizaje interactivo. Docencia Positiva. Fecha de consulta 4 de abril de 2020. Recuperado de http://www.profesoresuniversitarios.org.mx/recursos_didacticos.pdf 
Heriberto Niccolas Morales, Jaime Garnica González, Cristian Eduardo Sánchez Ortiz, Itzel San Martín Sampayo, Germán Reséndiz López, Noel Iván Toto Arellano y Ángel Monzalvo Hernández

Atkins, D., Brown, J. y Hammond, A. (2007). A Review of the Open Educational Resources (OER) movement: achievements, challenges, and new opportunities. (Reporte para la Fundación William and Flora Hewlett). Recuperado de http://www.hewlett.org/wpcontent/uploads/2016/08/ReviewoftheOERMovement.pdf

Bertalanffy, L. (1976). Teoría General de Sistemas. México: Fondo de Cultura Económica.

Bravo, J. L. (2000). El vídeo educativo. ICE de la Universidad Politécnica de Madrid. Recuperado de http://www.ice.upm.es/wps/jlbr/Documentacion/Libros/Videdu.pdf

Cabero, J.; Llorente, M. y Román, P. (2005). Las posibilidades del vídeo digital para la formación. Labor Docente. 4, 58-74.

Checkland, P. (1993). Pensamiento de Sistemas, Práctica de Sistemas. México: Grupo Noriega Editores.

Fundación Telefónica. (2016). La Sociedad de la Información en España 2016. España: UNIGRAF.

Instituto Nacional de Estadística y Geografía (INEGI). (2020, 17 de febrero). Comunicado de prensa Num. 103/20. Encuesta Nacional sobre Disponibilidad y Uso de Tecnologías de la Información en los Hogares (ENDUTIH) 2019. Fecha de consulta: 2 de abril de 2020. Recuperado de https://www.inegi.org.mx/contenidos/saladeprensa/boletines/2020/OtrTemEcon/ENDUTIH_2019 .pdf

Johansen, O. (1986). Introducción a la Teoría General de Sistemas. México: Limusa.

Marquès, P. (2018). La evaluación de los vídeos didácticos. Facultad de Educación, UAB. Fecha de consulta 4 de abril de 2020. Recuperado de http://peremarques.net/videoav2.htm

Mortera, F. y Villarreal, J. (2013). Producción estudiantil de videos educativos abiertos como materiales instruccionales para el nivel de educación secundaria: estudio de caso. XXI Encuentro Internacional de Educación a Distancia. Guadalajara, México: UDG Virtual. Recuperado de http://www.udgvirtual.udg.mx/remeied/index.php/memorias/article/view/153/69

Mosquera, I. (2017, 8 de mayo). El uso de vídeo en Educación. De espectadores a protagonistas: coaprendizaje. UNIR Revista. Universidad Internacional de la Rioja. Fecha de consulta: 3 de abril de 2020. Recuperado de https://www.unir.net/educacion/revista/noticias/el-uso-de-video-eneducacion-de-espectadores-a-protagonistas-coaprendizaje/549201748483/

Ramírez, M. A. y Burgos, J. V. (2012). Proyecto macro de la experiencia de investigación recursos educativos abiertos y móviles, para la formación de investigadores: redes académicas repositorio Dar y REA producidos. En Recursos educativos abiertos y móviles, para la formación de investigadores: Investigaciones y experiencias prácticas. (1. ${ }^{a}$ ed., p. 9-29). México: Crown Quarto. Recuperado de https://repositorio.tec.mx/handle/11285/577936

Rodríguez, R. A., López, B. S. y Mortera, F. J. (2017). El video como Recurso Educativo Abierto y la enseñanza de Matemáticas. Revista Electrónica de Investigación Educativa, 19(3), 92-100. https://doi.org/10.24320/redie.2017.19.3.936

Sosisky, G., Perazzo, M., Bardi, V. y Ruiz, M. (2007). Cómo evaluar sitios y recursos educativos de Internet. Ministerio de Educación de Argentina. Fecha de consulta 5 de abril de 2020. Recuperado 
Uso de videos en el estudio y comprensión de la Teoría de Sistemas y el Pensamiento de Sistemas: Propuesta de una guía para la búsqueda y selección

de https://www.educ.ar/recursos/93293/como-evaluar-sitios-y-recursos-educativos-deinternet\#gsc.tab $=0$

Van Gigch, J. P. (2006). Teoría General de Sistemas. 3ra. Edición. México: Editorial Limusa. 